\title{
Total phenolic content and in vitro evaluation of antioxidant activity of ethanol extract of Ganoderma amboinense By Nina Salamah
}




\title{
RESEARCH ARTICLE
}

\section{Total phenolic content and in vitro evaluation of antioxidant activity of ethanol extract of Ganoderma amboinense}

\author{
Nina Salamah, Mustofa Ahda, Sidiq Bimantara, Rizka Hanar \\ 31 \\ Department of Analitical Chemistry, Faculty of Pharmacy, University of Ahmad Dahlan, Semaki, Umbulharjo, Yogyakarta, Indonesia \\ Correspondence to: Nina Salamah, E-mail: ninasalamah1996@gmail.com
}

Received: May 26, 2017; Accepted: October 14, 2017

\begin{abstract}
Background: Ganoderma amboinense is rich in fibers, minerals, and vitamins. This antler-shaped mushroom contains various antioxidant compounds called polyphenols and flavonoids. Antioxidants can counteract or deactivate free radicals in plants and animals by turning them into less reactive compounds. The methods of compound extraction are numerous and with di erent effects on the concentration of active compounds. Hence, selecting a correct extraction method becomes necessary. Aims and Objectives: The aim of 21 stuidy is to compare two extraction methods, namely, extraction by maceration and Soxhlet extraction, based on the total phenolic contents and the antioxidant activities of the ethanol extracts ( 920 of G. amboinense. Materials and Methods: The ethanol extract was obtained from maceration and Soxhlet extraction. The total phenolic content of $96 \%$ ethanol extrac 10 G. amboinense was determined using ultraviolet-visible spectrophotometry with Folin-Ciocalteu reagent, while the antioxidant activity was assessed using the 2,2-diphenyl-1picrylhydrazyl method. Results: Thin-layer ch 27 latography produces ethanol extracts, from either maceration or Soxhlet extraction, that contain phenolic comp $26 \mathrm{ds}$. The total phenolic contents of the ethanol extracts $8 \mathrm{om}$ maceration and Soxhlet extraction are $26.72 \pm 1.13 \mathrm{mg} 8 \mathrm{llic}$ acid equivalents (GAE)/g of extract and $23.27 \pm 1.07 \mathrm{mg}$ GAE/g of extract, respectively. The effective scavenging $50 \%$ values of gallic acid and ethanol extract are, respectively, $2.476 \mu \mathrm{g} / \mathrm{ml}$ and $197.6 \mu \mathrm{g} / \mathrm{ml}$. Conclusion: Maceration produces ethanol extract of G. amboinense with higher total phenolic content than Soxhlet extraction. The research findings indicate that the ethanol extract has in vitro antioxidant activity.
\end{abstract}

KEY WORDS: Phenolic; Antioxidant; Ganoderma; Mushroom

\section{INTRODUCTION}

Extraction is a process of removing or separating active compounds in stems, leaves, and fruits. It is very important in determining the 19 mount of extractable active substance. The efficiency of conventional and non-conventional

\begin{tabular}{|l|l|}
\hline \multicolumn{2}{|c|}{ Access this article online } \\
\hline Website: www.njppp.com & \\
\hline &
\end{tabular}
extraction depends on critical parameters such as plant

matrix properties, chemical compounds, bioactive, and scientific expertis 18 There are various types of extraction methods, namely, maceration, infusion, digestion, decoction, percolation, and hot continuous extraction (Soxhlet). ${ }^{[2,3]}$ Each method has different strengths and weaknesses. The latest development of extraction method in medicinal plants uses liquid nitrogen as solvent. ${ }^{[4]}$ Odey et al ${ }^{[5]}$ found that the effectiveness of medicinal plants highly depends on extraction method and extract preparation.

This research analyzes two extraction methods, namely, maceration and Soxhlet extraction, for removing active compounds in Ganoderma mushrooms. These two methods are selected because they are simple and widely used. Meanwhile, Ganoderma mushrooms are sampled in this

\section{1}

National Joumal of Physiology, Pharmacy and Pharmacology Online 2018. O 2018 Nina Salamah, et al. This is an Open Access article distributed under the terms of the Creative Commons Attribution 4.0 International License (http://creative commons.org/icenses by $/ 4.0$ ), allowing third parties to copy and redistribute the material in any medium or format and to remix, transform, and build upon the material for any purpose, even commercially, provided the original work is properly cited and states its license. 
research because they have various pharmaceutically active compounds that exhibit antitumor, anticancer, antihypertensive, hypocholesterolemic, antihistaminic, antiplatelet, and antiretroviral/anti-HIV effects as well as immunomodulatory proteins. ${ }^{[6]}$ According to Boh et al. ${ }^{[7]}$ the active compounds are ganoderic acid, lucideric acid, ganodermic acid, ganoderenic acid, ganolucidic acid, polysaccharide, protein, amino acid, nucleotide, alkaloid, steroid, lactone, fatty acid, and enzyme. In addition, Rajasekaran and Kalaimagal ${ }^{[8]}$ state that the ethanol extract of Ganoderma has many phenolic compounds, flavone, and ascorbic acid that have protective effects against free radicals.

Considering the enormous potentials of Ganoderma, studies that aim to identify the effective and accurate extraction process for acquiring the active compounds of Ganoderma amboinense become necessary. This research compares a conventional extraction method, i.e., by maceration, with Soxhlet extraction and analyzes non-specific parameters, total phenolic contents, and antioxidant activities to determine the effectiveness of each method. Furthermore, ethanol extract with the highest total 2 henolic content is analyzed using diphenylpicrylhydrazyl 2,2-diphenyl-1-picrylhydrazyl (DPPH) method to identify its antioxidant activities.

\section{MATERIALS AND METHODS}

\section{Loss on Drying (LOD) Test of the Ethanol Extract of G. amboinense}

$1 \mathrm{~g}$ sample of G. amboinense extract was tested for LOD using halogen moisture analyzer. The amount of loss from the sample was recorded.

\section{Qualitative Test for Active Compounds using Thin-layer Chromatography (TLC)}

The extract solutions from maceration and Soxhlet extraction as well as a standard solution of gallic acid with a concentration of $2 \mathrm{mg} / \mathrm{mL}$ were sampled as many as $10 \mu \mathrm{L}$ and spotted to si 28 gel GF $_{254}$ (stationary phase) and with a solvent mixture (mobile phase) of toluene, ethyl acetate, and formic acid (ratio 6:4:0.8). After drying, the TLC plate was sprayed with two reagents, namely, form purple coloration in ferric chloride test $\left(\mathrm{FeCl}_{3}\right)$ and vanillin-sulfuric acid, and observed under visible lights.

\section{Determination of Total Phenolic Content ${ }^{[9]}$}

The total phenolic content of G. amboinense was determined using the method proposed by Murtijaya and Lim (2007) with modification. The gallic acid solution was made in various concentrations, i.e. $20-50 \mu \mathrm{g} / \mathrm{mL}$. Afterward, $300 \mu \mathrm{l}$ sar 25 es of each gallic acid solution were added by $1.5 \mathrm{ml}$ of Folin-Ciocalteu re 5 ent, and then, shaken. The mixture was allowed to stand for $3 \mathrm{~min}$, followed by the addition of
$1.2 \mathrm{ml}$ of $7.5 \% \mathrm{Na}_{2} \mathrm{CO}_{3}$. After $30 \mathrm{~min}$, the absorbance was measured at $598.5 \mathrm{~nm}$. Then, $25.0 \mathrm{mg}$ of the ethanol extract of $G$. amboinense was dissolved up to $10.0 \mathrm{ml}$ with $96 \%$ ethanol. This solution was 30 pensed as many as $300 \mu \mathrm{l}$ into the tube, added by $1.5 \mathrm{ml}$ of $\mathrm{F} 5 \mathrm{n}$-Ciocalteu reagent, and shaken. It was allowed to stand for $3 \mathrm{~min}$, followed by the addition of $1.2 \mathrm{ml}$ of $7.5 \% \mathrm{Na}_{2} \mathrm{CO}_{3}$. This mixture $77 \mathrm{~s}$ allowed to stand within the range of operating time (OT) for $30 \mathrm{~min}$ at room temperature. The absorbance of the extract solution was measured using ultraviolet visible (UV-Vis) spectrophotometer at a maximum wavelength of $598.5 \mathrm{~nm}$.

\section{9}

\section{Determination of DPPH Radical Scavenging Activity}

\section{Determination of $O T$}

Each sample was dispensed as many as $1 \mathrm{ml}$, added with $1 \mathrm{ml}$ of $0.15 \mathrm{mM} \mathrm{DPPH}$, and shaken. Then, the absorbance of this solution was observed until it was stable at minute $t$ at a wavelength of $517 \mathrm{~nm} \cdot{ }^{[10]}$

\section{Determination of the wavelength of maximum absorbance}

The wavelength of maximum absorbance of $\mathrm{D} 2 \mathrm{PH}$ solution was determined using the following technique: $1.0 \mathrm{ml}$ of 0.15 $\mathrm{mM}$ DPPH solution was add 24 with $1.0 \mathrm{ml}$ of ethanol p.a. and shaken homogeneously. The absorbance was measured at $400-600 \mathrm{~nm} \cdot{ }^{[10]}$

\section{Measurement of the absorbance of free radical scavenging using DPPH method}

Each concentration of ethanol extract was sampled by $1.0 \mathrm{ml}$. The negative control (DPPH + ethanol p.a.) and the positive control (DPPH + gallic acid) were made in various concentrations. The sample, negative control, and positive control were added by $1.0 \mathrm{ml}$ of $0.15 \mathrm{DPPH}$ solution and then shaken vigorously. The 2 plution was stored in the darkness for as long as the OT. The absorbance of the solution was measured at the maximum wavelength of DPPH with UV-Vis spectrophotometry. Blank was concomitantly prepared, containing ethanol p.a. solution. ${ }^{[10]}$

\section{Data analysis}

The data obtained from the aforementioned measurements were effective scavenging and the concentration of tested compounds. These data were then analyzed using linear regression to identify the concentration at which DPPH radicals were scavenged by $50 \%$ effective scavenging $50 \%$ $\left(\mathrm{ES}_{50}\right)$.

\section{RESULTS}

In this study, identification of G. amboinense includes some parameter such as qualitative test, total phenolic content, and 


\begin{tabular}{|c|c|c|c|c|c|c|c|}
\hline \multirow[t]{3}{*}{ Test } & \multicolumn{7}{|c|}{ Qualitative tests of phenolic contents } \\
\hline & \multirow[t]{2}{*}{$\mathrm{FeC}_{13}$} & \multirow[t]{2}{*}{ Folin-Ciocalteu } & \multicolumn{4}{|c|}{ TLC } & \multirow[t]{2}{*}{ Remarks } \\
\hline & & & Rf & UV 254 nm & UV 366 nm & $\mathrm{FeC}_{13}$ reagent & \\
\hline Maceration & Purple & Blue & $0.25,0.42$ & Black & Green & Violet & Positive \\
\hline Soxhlet extraction & Purple & Blue & $0.25,0.42$ & Black & Green & Violet & Positive \\
\hline
\end{tabular}

G. amboinense: Ganoderma amboinense, UV: Ultraviolet, TLC: Thin-layer chromatography

antioxidant activity of DPPH. The qualitative test appears the specific color and some count of spot on KLT plate [Table 1 and Figure 1]. The result of this research showed that the G. amboinense has phenolic compound which it showed from coloring test and Korean language test (KLT) test on the spot with Rf 0.25 and 0.42 .

\section{9}

With mobile phase (toluene:ethyl acetate:formic acid $=$ 6:4:0.8) and (A) $\mathrm{FeCl}_{3}$ reagent, (B) Vanillin-sulfuric acid reagent. Spotting: (1) and (5) extracts from maceration, (2) and (4) extracts from Soxhlet with 6 circulations, (3) a standard Solution of gallic acid, and (6) powdered crude drugs.

Other param $23 \mathrm{rs}$ for testing the G. amboinense quality are determinant the total phenol content, chemical yield, LOD, and antioxidant activity of DPPH. The result of this research was showed on Tables 2 and 3.

\section{DISCUSSION}

The extraction of active compounds in plants is influenced by several factors. The amount of the extracted compound has a significant influence on extraction method, solvent, and time possess. ${ }^{[1]}$ Therefore, this research describes the influence of different extraction methods, namely, maceration and Soxhlet extraction, on the active compounds of $G$. amboinense. Table 1 shows that the properties of the G. amboinense extracts produced in maceration and Soxhlet extraction have similarity. The active compounds that are extracted with ethanol in both methods consist of a phenyl group, which is not found in the aqueous and ethanolic extracts of Ganoderma lucidum. The active compounds of G. lucidum that are extracted using water and ethanol are not phenolic but petroleum-based. ${ }^{[12]}$ Phenolic content in the active compounds is identified using two qualitative tests in which the extracted active compounds $\mathrm{FeCl}_{3}$ reagent forms a complex of compounds with phenyl group. Furthermore, the phenyl group of the active compounds also reacts to Folin-Ciocalteu reagent (oxidation-reduction reaction) and forms blue coloration, i.e. color indicator for phenyl group. However, there is a slight difference between the results of maceration and Soxhlet extraction in the removal of active compounds. Both of these methods produce two purple spots on the TLC plates, indicating the presence of two active compounds with phenyl group [Table 1]. Each spot on the
Table 2: The test results of parameters in $\boldsymbol{G}$. amboinense

Parameters

Extraction methods

\begin{tabular}{lcc}
\cline { 2 - 3 } & Maceration & $\begin{array}{c}\text { Soxhlet } \\
\text { extraction }\end{array}$ \\
\hline Chemical yield (\%) & 10.88 & 7.86 \\
LOD (\%) & $4.72 \pm 0.22^{*}$ & $5.72 \pm 0.55^{*}$ \\
Total phenolic content & $26.72 \pm 1.13^{* *}$ & $23.27 \pm 1.07^{* *}$ \\
(mg GAE/g of extract) & & \\
\hline
\end{tabular}

Notes: *3-time replications; **6-time replications.

G. amboinense: Ganoderma amboinense, GAE: Gallic acid equivalents, LOD: Loss on drying

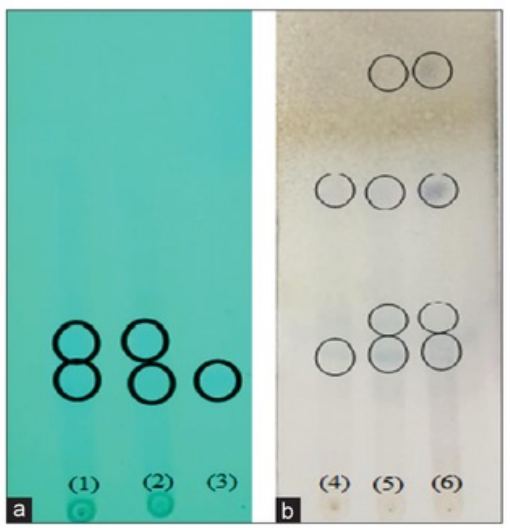

Figure 1: ( $a$ and $b$ ) The extraction of active compounds of Ganoderma amboinense using thin-layer chromatography

TLC plates shows dark color under 254-nm UV light and green under 366-nm UV light.

Spots on the TLC plate show that one of the active compounds has similar characteristics to gallic acid because its $\mathrm{Rf}$ value is 0.25 , which is close to the $\mathrm{Rf}$ value of gallic acid [Figure 1a]. Figure $1 \mathrm{~b}$ depicts the different numbers of spots when the TLC plate is sprayed with vanillin-sulfuric acid. Maceration and powdered crude drug have similar number of spots. Meanwhile, the Soxhlet technique only extracts two active compounds. However, this number of active compounds does not necessarily mean that Soxhlet extraction with six or more circulations is less effective than 24-h maceration in extracting the active compounds of $G$. amboinense because the active compounds may not react to the vanillin-sulfuric acid reagent. Alcohol compounds, phenols, steroids, and essential oils exhibit positive reactions to vanillin-sulfuric 


\begin{tabular}{|c|c|c|c|c|}
\hline Sample concentrations $(\mu \mathrm{g} / \mathrm{ml})$ & $\%$ inhibitions $(\mu \mathrm{g} / \mathrm{ml})$ & $\mathrm{ES}_{50} \underset{\text { extract }}{(\mu \mathrm{g} / \mathrm{ml})} \mathrm{EtOH}$ & $\%$ inhibitions $(\mu \mathrm{g} / \mathrm{ml})$ & $\mathrm{ES}_{50} \underset{\text { acid }}{(\mu \mathrm{g} / \mathrm{ml})}$ Gallic \\
\hline 0.39 & & & $5.6 \pm 2.9$ & \\
\hline 0.78 & & & $21.8 \pm 1.3$ & \\
\hline 1.56 & & & $46.8 \pm 2.5$ & 2.476 \\
\hline 3.12 & & & $83.3 \pm 2.8$ & \\
\hline 6.25 & & & $84.2 \pm 2.9$ & \\
\hline 12.5 & $0.9 \pm 2.6$ & & & \\
\hline 25 & $13.3 \pm 4.2$ & & & \\
\hline 50 & $21.9 \pm 2.7$ & 197.6 & & \\
\hline 100 & $33.1 \pm 2.0$ & & & \\
\hline 200 & $50.5 \pm 1.0$ & & & \\
\hline 400 & $65.7 \pm 1.8$ & & & \\
\hline
\end{tabular}

ES $_{50}$ : Effective scavenging $50 \%$

acid ${ }^{[13]}$ Aside from producing different spots on the TLC plates, maceration and Soxhlet extraction produce different parameters such as chemical yield, LOD, and total phenolic content. The chemical yield of maceration $(10.88 \%)$ is larger than the yield of Soxhlet extraction (7.86\%). As for the LOD of the ethanol extract of $G$. amboinense, maceration and Soxhlet extraction produce slightly different percentages, i.e., $4.75 \%$ and $5.72 \%$, respectively. The total phenolic contents produced in the two extraction methods are also different. The total phenolic content from maceration is $26.72 \mathrm{mg}$ gallic acid equivalents/g of extract, which is higher than Soxhlet extraction [Table 2]

Soxhlet extractor produces extracts with low phenolic content due to the presence of heat and oxygen in the process. Total phenolic compounds are oxidized in alkaline solution. Moreover, the polyphenol oxidase activity forms orthosemiquinone radicals that are reactive and may further react with amino compounds creating brown-colored products with high molecular weight. ${ }^{[14]}$ Heating vegetables at $60^{\circ} \mathrm{C}$ reduce the phenolic contents of several compounds significantly. Some phenolic compounds are easily oxidized particularly in alkaline environment and due to polyphenol oxidase activity ${ }^{[15]}$ Compared to 24 -h maceration, the chemical yield of Soxhlet extraction is lower. In prolonged Soxhlet extraction, the total phenolic contents decline significantly. When the total phenolic contents of the extract decrease, the effectiveness of G. amboinense as an antioxidant also decreases. ${ }^{[16]}$ Therefore, a high total phenolic content commonly associates with high antioxidant activity. Maceration produces extracts with higher total phenolic content than Soxhlet extraction. The antioxidant activities were analyzed using the DPPH method. The comparison between the antioxidant activities of the ethanol extract of G. amboinense and gallic acid is indicated by $\mathrm{ES}_{50} . \mathrm{ES}_{50}$ represents the concentration of tested compound required for reaching an effectiveness of $50 \%$ free radical scavenging. This value is determined using linear regression analysis between the concentration of the tested compound and the percentage of free radical scavenging. Table 3 shows that gallic acid has more free radical-scavenging potential (ES $2.476 \mu \mathrm{g} / \mathrm{ml}$ ) than the ethanol extract of $G$. amboinense $\left(\mathrm{ES}_{50} 197.6 \mu \mathrm{g} / \mathrm{ml}\right)$. Gallic acid establishes higher scavenging

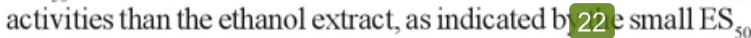
value of gallic acid. The $\mathrm{ES}_{50}$ value is inversely proportional to the percentage of free radical scavenging. The higher the $\mathrm{ES}_{30}$ value, the higher the concentration required in producing $50 \%$ free radical-scavenging activities, and hence, the smaller the scavenging potential. G. lucidum is the same family with $G$. Amboinense and it is reported that the antioxidant activity of ethanolic extract $G$. lucidum with ES50 13, $16 \mu \mathrm{g} / \mathrm{ml} .^{[17]}$ Based on it, if we compare the potensial antioxidant of G. lucidum higher than G. amboinense.

The antioxidant activities of gallic acid and the ethanol extract are 13 yzed statistically using normality test, Levene's test, Kruskal-Wallis test, and Mann-Whitney U-test. The significance value $(\alpha)$ from the nor 12 ity test is $<0.05$ (i.e., 0.231), meaning that the data are normally distributed. The test for homogeneity of variance with Levene's test shows a significance value between 0.005 and 0.05 , which represents data with non-homogeneous variance. In addition, the significance value produced in the non-parametric test, i.e. the Kruskal-Wallis test, with a confidence level of $95 \%$ is 0.0009 . Since it is $<0.05$, the test confirms that the difference between the various treatment groups is significant. The last test is the Mann-Whitney U-test that compares the treatment results between the treatment groups. The p-value of MannWhitney U-test is 0.008 , which is $<0.05$, indicating that the antioxidant activities between gallic acid and the ethanol extract are significantly different.

\section{CONCLUSION}

Extraction by maceration produces a higher total phenolic content than Soxhlet extraction. The total phenolic content 
shows antioxidant potentials of the ethanol extract of G. amboinense. The antioxidant activity of the ethanol extract is smaller than gallic acid, which is a type of polyphenol

\section{ACKNOWLEDGMENTS}

15

The author thanks to the Ministry of Research and Technology-Higher Education for funding this recearch under the scheme of Research Grants for Junior Lecturers.

\section{REFERENCES}

1. Azmir J, Zaidul IS, Rahman MM, Syarif KM, Mohamed A, Sahena F, et al. Techniques for extraction of bioactive compounds from plant materials: A review. J Food Eng. 2013;117:426-36

2. Majekodunmi SO. Review of extraction of medicinal plants for pharmaceutical research. Merit Res J Med Med Sci. 2015;3(11):521-7.

3. Pandey A, Tripathi S. Concept of standardization, extraction and pre phytochemical screening strategies for herbal drug J Pharmacogn Phytochem. 2014;2(5): 115-9.

4. Solanki R, Nagori BP. New method for extracting phytoconstituents from plants. Int $\mathrm{J}$ Biomed Adv Res. 2012;3(10):770-4.

5. Odey MO, Iwara IA, Udiba UU, Johnson JT, Inekwe UV, Asenye ME, et al. Preparation of plant extracts from indigenous medicinal plants. Int J Sci Technol. 2012;1(2);688-92.

6. Dunham M. Potential of Fungi Used in traditional Chinese Medicine: II Ganoderma; 2000. Available from: http://www. oldkingdom/UGprojects/Mark-Dunham/Mark-Dun-ham.html. [Last accessed on $2014 \mathrm{Apr}$ 02].

7. Boh $\mathrm{B}$, Hodžar D, Dolničar D, Berovič M, Pohleven F. Isolation and quantification of triterpenoid acids from Ganoderma applanatum of Istrian origin. Food Technol Biotechnol. 2000;38:11-8.

8. Rajasekaran M, Kalaimagal C. In vitro antioxidant activity of ethanol extract of medicinal mushroom. Ganoderma lucidum.
J Pharm Sci Res. 2011;3(9): 1427-33.

9. Murtijaya J, Lim YY. Antioxidant properties of Phylanthus amarus extracts as affected by different drying methods. LWT Food Sci Technol. 2007:40: 1664-9.

10. Da'i M, Wahyuni AS, Trisharyanti DK, Azizah T, Suhendi A, Saifudin A. Antioxidant activity of Phyllanthus niruri L. herbs: In vitro and in vivo models and isolation of active compound. Natl J Physiol Pharm Pharmacol. 2016;6:2-37.

11. Bandar H, Hijazi A, Rammal H, Hachem A, Saad Z, Badran B Techniques for the extraction of bioactive compounds from Lebanese Urtica dioica. Am J Phytomed Clin Ther. 2013;1(6):507-13.

12. Fakoya S, Adegbehingbe KT, Ogundiimu AA Biopharmaceutical assessment of active components of Deadaleopsis confragosa and Ganoderma hucidum. Open J Med Microbiol. 2013;3:135-8.

13. Sudirman LI. Detection of antimicrobial compounds isolated from several tropical lentinus by bioautographic Method. Hayati J Biosci. 2005; 12(2):67-72.

14. Pratt DE. Natural Antioxidant From Plant Material Washington DC: American Chemical Society; 1992.

15. Ho CT. Phenolic compound in food. In: Huang MT, Ho CT, Lee CY, editors. Phenolic Compound in Food and Their Effects on Health II. Washington DC: American Chemical Society; 1992.

16. Bondet V, Williams WB, Berset C. Kinetics and mechanisms of antioxidant activity using the DPPH free radical method. LWT Food Sci Technol. 1997;30:609-15.

17. Sheikh IA, Vyas D, Ganaie MA, Dehariya K, Singh V. HPLC determination oh phenolics and free radical scavenging activity of ethanolic extract of two polypore mushrooms. Int J Pharm Pharma Sci. 2014;6(2):679-84

How to cite this article: Salamah N, Ahda M, Bimantara S, Hanar R. Total phenolic content and in vitro evaluation of antioxidant activity of ethanol extract of Ganoderma amboinense. Natl J Physiol Pharm Pharmacol 2018;8 (Online First). Doi: 10.5455/njppp.2018.8.0518614102017

Source of Support: Nil, Conflict of Interest: None declared. 


\section{Total phenolic content and in vitro evaluation of antioxidant activity of ethanol extract of Ganoderma amboinense}

ORIGINALITY REPORT

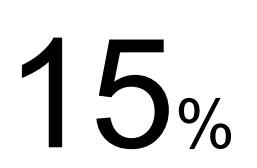

SIMILARITY INDEX

PRIMARY SOURCES

1 www.ejmanager.com

Internet

93 words $-3 \%$

2 www.mdpi.com

Internet

37 words $-1 \%$

3 Kherde, Piyush, Neelam Mishra, Shrinivas Chitta, and

Shailesh Gahukar. "Influence of sawdust on peak

26 words $-1 \%$

expiratory flow rate in sawmill workers of central India working in

unprotected environment and its correlation with duration of

exposure", National Journal of Physiology Pharmacy and

Pharmacology, 2016.

Crossref

4 Ramalingam, Latha, and Rajalakshmi Ramesh. "Heart rate variability is reduced in sedentary young females

23 words $-1 \%$ with higher body mass index", National Journal of Physiology

Pharmacy and Pharmacology, 2016.

Crossref

5 apb.tbzmed.ac.ir

Internet

20 words $-1 \%$

6 Han, Lu, Caizhen Liang, and Xican Li. "Protective affect against hydroxyl radical induced DNA damage 15 words $-1 \%$ and antioxidant mechanism of Begonia fimbristipula", Oxidants and Antioxidants in Medical Science, 2013. crossref

7 Brighente, I.M.C., M. Dias, L.G. Verdi, and M.G. Pizzolatti. "Antioxidant Activity and Total Phenolic

13 words $-<1 \%$ 
Content of Some Brazilian Species", Pharmaceutical Biology, 2007.

Crossref

8 Zhang, Ang, Yulin Fang, Hua Wang, Hua Li, and Zhenwen Zhang. "Free-Radical Scavenging

13 words $-<1 \%$ Properties and Reducing Power of Grape Cane Extracts from 11

Selected Grape Cultivars Widely Grown in China", Molecules, 2011.

Crossref

9 www.omicsonline.org

Internet

11 words $-<1 \%$

10 harvester.um.edu.my

Internet

11 words $-<1 \%$

11 Sharma, Sanjay, Seema Gupta, Sanjeev Bhat, Zahid Gillani, Dinesh Kumar, and Rajesh Kumar.

11 words $-<1 \%$ "Efficacy and safety of tirofiban as an adjunctive therapy in patients with acute ST-segment elevation myocardial infarction undergoing percutaneous transluminal coronary angioplasty", National Journal of Physiology Pharmacy and Pharmacology, 2016.

Crossref

12 hydra.hull.ac.uk Internet

10 words $-<1 \%$

13 odontoclinica.org Internet

10 words $-<1 \%$

14 bmccomplementalternmed.biomedcentral.com Internet

10 words $-<1 \%$

15 Heriansyah, Teuku, Titin Wihastuti, Kenty Anita, Agustin Iskandar, Riski Suhendra, Patan Setiabudi, 9 words $-<1 \%$ and Lintang Sishartami. "Atherogenesis inhibition by darapladib administration in ayslipidemia model Sprague-Dawley rats", National Journal of Physiology Pharmacy and Pharmacology, 2015. 
16 Dai, Muhammad, Arifah Wahyuni, Ika DK, Tanti Azizah, Andi Suhendi, and Azis Saifudin.

9 words $-<1 \%$ "Antioxidant activity of Phyllanthus niruri L. herbs: in vitro and in vivo models and isolation of active compound", National Journal of Physiology Pharmacy and Pharmacology, 2016.

Crossref

17 Taous Khan. "Enzyme inhibition and radical scavenging activities of aerial parts of Paeonia 9 words $-<1 \%$ emodi Wall. (Paeoniaceae)", Journal of Enzyme Inhibition and Medicinal Chemistry, 6/1/2005 Crossref

18 prr.hec.gov.pk Internet

9 words $-<1 \%$

19 Azmir, J., I.S.M. Zaidul, M.M. Rahman, K.M. Sharif, A. Mohamed, F. Sahena, M.H.A. Jahurul, K.

9 words $-<1 \%$ Ghafoor, N.A.N. Norulaini, and A.K.M. Omar.

"Techniques for extraction of bioactive compounds from plant materials: A review", Journal of Food Engineering, 2013.

Crossref

20 documents.mx

Internet

9 words $-<1 \%$

21 www.sciepub.com Internet

9 words $-<1 \%$

22 Melek Col Ayvaz. "Antioxidant activity of Trachystemon orientalis (L.) G. Don (Borage) grown 8 words $-<1 \%$ and eaten as food in Ordu, Turkey", Herba Polonica, 2015 crossref

23 www.ptfos.unios.hr Internet

8 words $-<1 \%$

24 HOANG VAN HA. "PEANUT SKIN ANTIOXIDANTS", 8 words $-<1 \%$ Journal of Food Lipids, 9/2007 Crossref 
26 HOSSAIN, Sheikh Julfikar, Iyo TSUJIYAMA, Mikako TAKASUGI, Md. Ashabul ISLAM, Rajat Shuvra BISWAS, and Hitoshi AOSHIMA. "Total Phenolic Content, Antioxidative, Anti-amylase, Anti-glucosidase, and Antihistamine Release Activities of Bangladeshi Fruits", Food Science and Technology Research, 2008. Crossref

27 KAYA, Gülen İrem, SOMER, Nehir Ünver, KONYALIOĞLU, Sibel, YALÇIN, H. Tansel, 8 words $-<1 \%$ YAVAŞOĞLU, N. Ülkü Karabay, SARIKAYA, Buket and ÖNÜR, Mustafa Ali. "Antioxidant and antibacterial activities of Ranunculus marginatus var. trachycarpus and R. sprunerianus", TÜBITAK, 2010.

Publications

28 Fernandes, Felipe Hugo Alencar, and Hérida Regina 7 words $-<1 \%$ Nunes Salgado. "Gallic Acid: Review of the Methods of Determination and Quantification", Critical Reviews in Analytical Chemistry, 2015. Crossref

29 Rehakova, Z., V. Koleckar, F. Cervenka, L. Jahodar, 6 words $-<1 \%$ L. Saso, L. Opletal, D. Jun, and K. Kuca. "DPPH Radical Scavenging Activity of Several Naturally Occurring Coumarins and Their Synthesized Analogs Measured by the SIA Method", Toxicology Mechanisms and Methods, 2008. Crossref

30 Snehal Salunke, Vishal Pande, Prakash Kendre, Somnath Vibhute. "Effect of Standardized 6 words $-<1 \%$ Polyherbal Formulations on Blood Glucose Body Weight Food and Water Consumption of Rats", Pharmaceutical Sciences, 2015 Crossref

31 Sumaira Saleem, Gulzar Muhammad, Muhammad Ajaz Hussain, Syed Nasir Abbas Bukhari. " A 6 words $-<1 \%$ comprehensive review of phytochemical profile, bioactives for 
pharmaceuticals, and pharmacological attributes of ",

Phytotherapy Research, 2018

crossref 